\title{
Erratum zu: Smart entscheiden in Zeiten der Veränderung
}

Rafael E. Huber

Die aktualisierte Version des Kapitels 13 dieses Buches finden Sie unter https://doi.org/10.1007/978-3-662-58411-8_13 
Erratum zu: Kapitel 13 in: C. Negri

(Hrsg.), Führen in der Arbeitswelt

4.0, Der Mensch im Unternehmen:

Impulse für Fach-

und Führungskräfte https://doi.

org/10.1007/978-3-662--

58411-8_13

Der zweite Absatz auf der Seite 174 wurde ver-

sehentlich mit einige Fehler veröffentlicht und wurde korrigiert. 